\title{
Paideusis
}

\section{Enacting a 'Curriculum of Life': Mindfulness and Complexity Thinking in the Classroom}

Sean Roswell Park

Volume 16, Number 3, 2007

URI: https://id.erudit.org/iderudit/1072488ar

DOI: https://doi.org/10.7202/1072488ar

See table of contents

Publisher(s)

Canadian Philosophy of Education Society

ISSN

0838-4517 (print)

1916-0348 (digital)

Explore this journal

Cite this article

Park, S. (2007). Enacting a 'Curriculum of Life': Mindfulness and Complexity Thinking in the Classroom. Paideusis, 16(3), 45-55.

https://doi.org/10.7202/1072488ar
Article abstract

This paper advances Portelli and Vibert's (2001) concept of a 'curriculum of life' as a central organizing concept in education. A curriculum of life, defined as a "curriculum that is grounded in the immediate daily world of students as well as in the larger social, political contexts of their lives" (Portelli \& Vibert, 2001 , p. 63) is, de facto, at the centre of student learning. I argue that teachers can engage with this immediate daily world and enact a curriculum of life by practicing mindfulness and complexity thinking as ways of valuing relationships and engagement. Complexity thinking in education, which draws upon themes of emergence, self-organization and non-linearity, leads us to a relational ethics that compels educators to take mindful responsibility for how our actions and responses affect the world.
This document is protected by copyright law. Use of the services of Erudit (including reproduction) is subject to its terms and conditions, which can be viewed online.

https://apropos.erudit.org/en/users/policy-on-use/ 


\title{
Enacting a 'Curriculum of Life': Mindfulness and Complexity Thinking in the Classroom
}

\author{
SEAN PARK \\ McMaster University, Canada
}

\begin{abstract}
This paper advances Portelli and Vibert's (2001) concept of a 'curriculum of life' as a central organizing concept in education. A curriculum of life, defined as a "curriculum that is grounded in the immediate daily world of students as well as in the larger social, political contexts of their lives" (Portelli \& Vibert, 2001, p. 63) is, de facto, at the centre of student learning. I argue that teachers can engage with this immediate daily world and enact a curriculum of life by practicing mindfulness and complexity thinking as ways of valuing relationships and engagement. Complexity thinking in education, which draws upon themes of emergence, self-organization, and non-linearity, leads us to a relational ethics that compels educators to take mindful responsibility for how our actions and responses affect the world.
\end{abstract}

\section{An Alternative Vision: Mindfulness and Complexity Thinking}

Portelli and Vibert (2001) described a 'curriculum of life 'as:

- an approach to pedagogy that gives coherence to divergent aspects of school life

- implicit in the curriculum, school organization/policy, disciplines, school/community relations, pedagogy, and culture of a school

- a way of addressing questions of who we are and how we live well together

- seeing the immediate and urgent experiences, issues, and questions of students as the content of the classroom.

They argued that the recent activity to define, measure, and enforce common standards in education has neglected the most important step of actually directing resources and support to improving conditions across our nation's schools. The problem with the accountability, common standards, and standardized testing movement is that it tends toward mechanistic and technocratic visions of curriculum that do not reflect the reality of the classroom. This reality is the lived experience of teachers and students and includes issues of social inequity, discrimination, poverty, racism, environmental degradation, and violence and it is these issues that are "becoming more and more the irresistible content of the classroom" (p. 79). Evaluating quality, they argue, would be better achieved by helping teachers to develop and engage local assessment that can take this content into account.

I agree with Portelli and Vibert's claim that, in practice, standards are local and interpretive and should be framed in context of a curriculum of life. I want to expand on their argument in this paper to say that engaging in such a curriculum also requires that we help teachers to see and work with the

(C) Copyright 2007. The author, Sean Park, assigns to Paideusis the right of first publication and educational and non-profit institutions a non-exclusive license to use this document for personal use and in courses of instruction provided that the article is used in full and this copyright statement is reproduced. Any other usage is probibited without the express permission of the author. 
reality of students' lives as the curriculum. If we are to make a curriculum grounded in our daily lives as the central, organizing concept in education, we need to support the development of deep listening into what is happening in classrooms. This listening cannot make up for under-funded classrooms or lack of support for professional development, but it is essential if teachers continually find themselves in situations where they have no choice but to enact a curriculum of life ${ }^{1}$.

I view this deep listening as being connected to Cohen's (2006) contention that, to better engage with students, educators need to look at the 'gap' between how they present themselves and what they are experiencing within. Cohen's position is that as the gap increases, effectiveness diminishes. As the gap decreases, effectiveness increases. He defines effectiveness as the capacity to personally engage with students, have students personally engage with each other, develop a classroom atmosphere of animation and community, and engagement with the material. A significant proportion of the phenomenal success of educators who close this gap, he argues, "is connected to the self-knowledge gained from attention to and work with their inner life that allows them to have advanced ability to be fully present in the moment" (emphasis Cohen, p. 31).

As Cohen (2006) and Bai (2001) have done, I also wish to advocate for the importance of mindfulness as a way of grounding in the immediate daily world of one's self, that of students and the present moment of their intersections. In addition to, but beyond what we know in a linguisticconceptual way about teaching and learning, knowing how one acts in response to the world requires direct knowledge of our experience with students, the awareness unconstrained by language and concept that mindfulness affords us. I will also advocate that, within the interaction between our conceptual and non-conceptual awareness, complexity thinking emerges as way of framing and unframing our actions as teachers in a curriculum of life. Complexity thinking, defined as "somewhere between a belief in a fixed and fully knowable universe and a fear that meaning and reality are so dynamic that attempts to explicate are little more than self-delusions" (Davis \& Sumara, 2006, p. 4), requires the capacity to sustain the contradiction of having to teach official content and responding to the unofficial yet irresistible content of the classroom.

Working with the relationship between mindfulness and complexity thinking, at both intellectual and embodied levels, we can start to close the gap between how teachers are experiencing curriculum and how they act, and to sustain the above contradiction. I will discuss complexity as it relates to education to show how our relationships and engagement with students necessitates ways of fitting ourselves to the reality of the classroom. Connecting with Bai's (2003) relational ethics, I argue for mindfulness as a way of connecting complexity thinking to engaging a curriculum of life.

\section{Complexity Thinking and Engagement}

Complexity thinking recognizes human interaction as self-organizing, unpredictable yet patterned, and co-evolving. It also represents a way of acting that is oriented by practical, ethical, and normative concerns about how we should act with an appreciation of complexity (Davis and Sumara, 2006). My main concern with complexity, which I will describe shortly in some detail, is with what Dell (1982) and Burris (2005) described as the 'epistemological errors' made by therapists and educators. These are errors that involve a misunderstanding or refusal of 'reality' - understood as a co-construction arising from mutually constituted human interactions, not something objective - and come in two basic forms: passive and active. 'Passive' epistemological errors are failures to acknowledge reality, also known as 'denial' (Burris, p. 6). 'Active' epistemological errors involve attempts to conform others to one's

\footnotetext{
1 The choice to respond to students' lives as the context for curriculum is made difficult when the official curriculum fails to account or make room for lived experience. But to abandon the official curriculum altogether is not the answer because knowing the discourse of those in power, of those that shape the curriculum, is a necessary aspect of knowing how to identify, critique, learn from and transform our societal institutions
} 
expectations or needs. This also involves trying to get others to conform to one's very conception of reality.

Burris argued that teachers commit passive errors in valuing content over relationships when they treat knowledge as something independent from the knower, locatable only within an individual brain, and transmitable between minds. These assumptions are considered 'errors' because learning and content happen through interaction and "it is in relating to people and texts and ideas that individuals learn; it is through these relationships that individuals embrace and change content and, importantly, help to generate innovative collective knowledge (Davis \& Simmt, 2003 in Burris, p. 41).

Active epistemological errors are rooted in three objectivist assumptions that Burris considered flawed; namely, that control is determined by cause and effect, students' behaviours and learning are caused by teachers' actions, and chaos is to be avoided (p. 11). From a complexity perspective, teachers are unable to force compliance and learning because they can only invite actions from others through relationships - "the nature of others' actions is never determined by what I do, only by their [students'] own particular structures" (p. 12). Control and direction, from this perspective, are emergent from the gestures and responses occurring between teachers and students and reminds us that "we must fit ourselves to the situation" (Dell, 1982, p. 9, emphasis in the original) and create the conditions that enable students to connect with each other, the teacher, and the content. Carl Rogers (1995) aptly intuited this 'fitting' in student-teacher relationships when he said:

As I try to listen to myself and the experiencing going on in me, and the more I try to extend the same listening attitude to another person, the more respect I feel for the complex processes of life. So I become less and less inclined to hurry in to fix things, to set goals, to mold people, to manipulate and push them in the way that I would like them to go...The more I am simply willing to be myself, in all this complexity of life, and the more I am willing to understand and accept the realities in myself and the other person, the more change seems to be stirred up. (pp. 21-22)

In this way, as Portelli and Vibert argued, students cannot be 'managed' but 'engaged'. Differentiating between the notions of management and engagement is critical because they represent perspectives on how change occurs in two very different types of systems.

Systems can be conceptualized as being simple, complicated, and complex. Simple and complicated systems are best understood in terms of how physical objects, such as machines, operate. The functioning of a car, for example, can be understood as a sum of its parts. If the right parts are in their proper place, the car will function predictably and can be controlled to produce specific outcomes. You can take apart and put a car back together and it will still work. Problems can be managed by replacing or repairing parts. Complex systems, however, behave 'organically' because they grow, change, and collapse as a function of the changing relationships between the parts in the system. If you take apart a complex system, you cannot piece it back together as the very 'life' of the system is dependent upon the existence of all the connections working in parallel with each other (Kauffman, 1995).

Our knowledge of simple and complicated systems is rooted in classical Newtonian mechanics, the foundation of modern science. According to Heylighen, Cilliers and Gershenson (forthcoming 2007), the influence of a Newtonian worldview was immense because of the mechanistic paradigm's compelling "simplicity, coherence and apparent completeness" (p. 3). The biological and social sciences have a long history of adopting this worldview, however, with the relatively recent developments in fractal mathematics, quantum mechanics, and chaos theory, this worldview is shifting towards seeing the biological and social phenomena as emergent, non-linear and self-organizing (ibid, p. 5). In the 1980s complexity science developed as an alternative paradigm pointing to non-linearity and selforganization as common features across physical, biological, and social systems. The study of social systems, like schools and classrooms, as complex adaptive systems (CAS) focuses on how diverse 
individuals interacting with each other both produce and co-evolve with the emergent behaviour of the group (Holland, 1995). Interactions between people are not controlled centrally but by 'consensual frames' (Fogel, 1993), biological, psychological, and cultural influences that shape, and are shaped by, how people create coherence and agreement ${ }^{2}$. Decentralized control and consensual frames are key for understanding the role of engagement in the sense that, as teachers are part of the system (i.e. the classroom) and cannot have a bird's-eye view, they can only bring about actions with students through a dialogue shaped by working through the consensual frame.

Management requires that one has both a top-down, bird's-eye perspective and the ability to control interactions. You can manage a car because it is a complicated system that can be taken apart and put back together again. Epistemological errors are committed in treating students as objects that can be managed because teachers' actions are mutually constituted with students' in a co-evolving consensual frame. This point is critical to my understanding of why the "immediate and urgent experiences, issues, and questions of children in schools" are the consensual frames that shape the content of the classroom.

Complexity thinking and engagement bring up three distinct yet overlapping themes relevant to appreciating the relationship between education and complexity. The first theme is emergence. Bereiter (2002), in speaking about analyzing how groups of students work together, said:

The mark of a really successful design or problem-solving meeting is that something brilliant comes out of it that cannot be attributed to an individual or to a combination of individual contributions. It is an emergent, which means that if you look at a transcript of the meeting you can see the conceptual object taking shape but you cannot find it in the bits and pieces making up the discourse. (p. 183)

Bereiter is referring to a phenomena (a conceptual object) emerging through the mutual constitution of participants in a dialogue. The system (perhaps a small group of students), the individual participants, and the phenomena are interrelated or 'structurally coupled' (Maturana and Varela, 1987). In other words, systems and participants are bringing forth and brought into being because of their relationships to one another. The notion of the self, for example, can only emerge in relation to the other. The simultaneous, paradoxical, and two-way relationship of bringing forth and brought into being means that participants are 'mutually specifying' (Varela, Thompson, and Rosch, 1991). The change in one participant or system is always coupled with a response from interconnected parts, which is fed back to the contributor. Knowledge as a conceptual and dynamic object is understood in the process of mutual specification as an emergent product brought about by and bringing about the relationships unfolding among people in dialogue. In this way the relationships are the content.

Uncertainty, the second theme, concerns the unpredictability of complex phenomena. 'Complex' is used to refer to the tangled and dynamic web of participants, systems, and relationships that influence (and are influenced by) an object of study. If we could account for everything in this web, we would have a description of the entire system itself. This is not possible, however, because as observers we are necessarily part of the system and cannot remove ourselves from 'it' to describe it fully or objectively. Because of this entangled web of affairs, change is non-linear because small shifts and perturbations can ripple through a web of relationships causing major transformations. Similarly, large shifts may only result in small transformations to interrelated systems. Student learning is largely non-linear and unpredictable to the degree that one can never know with much precision when shifts and leaps in worldview or self-awareness, for example, will happen. The so-called 'aha' and 'eureka' moments educators often look for in their students occur in unexpected contexts, like on a walk to the

\footnotetext{
${ }^{2}$ Fogel uses the example of a mother pulling her child up to a sitting position to illustrate that the co-regulating of their actions and responses requires a form of mutual consent for the process to have coherence (p. 18).
} 
park or in the shower at the end of the day. These moments cannot be controlled or expected to occur more frequently by sitting in class for longer hours.

Finally, complex systems, like the human body or an ecosystem, are 'adaptive', meaning that the system (learners) can learn. Learners can include social and classroom groupings, programmes, faculties, communities, bodies of knowledge, languages, cultures, species, individuals, and cognitive structures, among other things (Davis \& Sumara, 2006). Learning is not controlled or directed by external agents or some sort of internal homunculus, but through a process of self-organization whereby a system increases in complexity (becomes more organized). When a number of diverse learners relate to each other over time, their relationships will tend to self-organize into patterns that enable the system to maintain identity while the parts constituting the system are continuously undergoing transformation. This is referred to as a 'bottom-up' process and we see that the emergent outcomes of self-organizing process are understood in terms of the patterned relationships and exchanges between learners. As the relationships between the parts change, the complexity of the system can change. Because of mutual specification, the process is also 'top-down' in that the complexity and organization of the system (the emerging products and patterns) can change how the learners are interacting.

\section{Relational Ethics}

Let us not forget that patterns are something that is perceived. Patterns are not independent of perception, which means that the perceiver's act of perception and interpretation is part of the pattern perceived...Perceiving patterns is an act that psychologically transcends the subject-object duality... [and] brings about a sense of co-emergence or unity of the subject and object. Through such acts of intersubjectivity, a relational ethic is born. (Bai, 2003, p. 25)

Identifying, correcting, and avoiding epistemological errors, what we can consider as part of an educational ethics, is not just about how we act as teachers because how we act is connected to how we think and perceive (epistemology) (Bai, 2003). Complexity is important because it draws our attention to the co-emergence of subject and object, and ultimately to a 'relational ethics'. To understand mindfulness and complexity in context of our responsibilities as educators, this relational ethic necessitates that we understand how we are always implicated in our engagement with students.

Understanding our engagement with students as process of complexity requires that we take seriously our mutuality with students and pay close attention to the subtle ways in which we can perpetuate the division of teacher from student and relationships from content. Griffin (2002), as one example, argued that much of the popular writing on applications of complexity to human interactions (e.g. Wheatley, Gell-Mann, Holland, and Senge) problematically avoids the paradox of co-emergence and falls into a Kantian 'both... and' conception of ethics. He used Sennett's The Corrosion of Character, a book on how corporations have eroded the quality of life and communities throughout the US, as an example of a common perception that systems like capitalism and corporations can hold ethical responsibilities. These systems are conceived as entities unto themselves that can be responsible for 'their' actions. However, blame and punishment has to be located so we adopt a view that it is also particular individuals (leaders) that are ethically responsible. This is a 'both... and' way of thinking in that it is both the 'system' and a few individuals that are responsible. He posited that everyone is labeled as a victim of the system and of leaders, leaving our deliverance to heroes and obscuring our collective co-implication in actions that bring about suffering.

Griffin offered an account of how seeing action as subject to both the laws of nature and free will, a basis for Immanuel Kant's ethics, has influenced our thinking about systems and ethics in problematic ways. 
Kant held that we are truly human in setting on-going goals for our actions, but that we can also think about nature using a particular understanding of on-going goal setting. That particular understanding amounts to an 'as if way of thinking...the system dynamically unfolds a form, a goal of its own, namely, to realize a mature form of itself. But that is not to say that the dynamic is setting the goal. It is the human scientist observing and hypothesizing who is thinking and testing 'as if' the system were setting and unfolding such a goal itself. (p. 5)

Nature was seen by Kant as self-organized wholes that realized these human-postulated 'as if' goals. The parts exist to create the whole. Human action is considered separate and autonomous from this self-organization because it is the human that ascribes the 'as if goal to the system. Kant, however, stated that human action could not be understood in 'as if terms because such a move would remove autonomy from the individual to some human system trying to achieve a goal. The autonomy of the individual was to be maintained, important to Kant because he lived in an age of extreme religious dogma. Instead, an individual's ethics were guided by the categorical imperative: act 'as if all could do our actions universally.

This 'both....and' approach is problematic for Griffin on at least three levels. First, it proposes that we can have both external observers and self-organizing systems (e.g. nature, organizations, classrooms) in which the observer is taking part. This perspective avoids the very paradox of the observer being part of the system. Second, it describes the movement and change of a system as a consequence of the observer's hypotheses and not because the system is itself the cause of change. Third, paradox is eliminated so that the entire system can be described, thus avoiding the limitations of being locally situated in a system.

Richmon, a philosopher on complexity and education administration, pointed to how this 'both... and' approach is taken up in educational leadership. He points to the very popular complexityinspired work of Michael Fullan (2003), who said:

the eventual solution for ... educational reform is that the vast majority of people in the system must end up 'owning the problem' and be agents of the solutions ... [T] his is absolutely not to say that the problem should be handed over to people; we need instead to create the conditions and processes that will enhance the likelihood that we move down the path of increasingly greater ownership and commitment. (p. 23)

Richmon (2006) commented that Fullan avoids the paradox by suggesting that if reform cannot be accomplished through the will of the few, then the will of the few can enable the conditions whereby the many will adopt the will of the few. Richmon translated this into We can't control people, but we can control the conditions which in turn control people', which he aptly termed 'determinism, once removed' (Richmon, 2006, p. 17).

Complexity as uncertainty, emergence, and adaptation can, in the context of identifying, correcting or avoiding epistemological errors, be interpreted as 'determinism once removed' to fit the needs of educators who think that if learning cannot be controlled directly, then they can step into and out of their structurally coupled relationships with students and somehow set the conditions that will cause students to learn towards some end envisioned by the educator.

'Fitting ourselves to the situation' is not a case of handing problems and control over to students because educators never have it in the first place. If we are 'structurally coupled' in that our actions affect, and are affected by others, we can see the 'other' as "an interpenetrating matrix of relationships, and thus forming an inter-being with the self' (Bai, 2003, p. 27). Working with this interbeing, the relationships between beings, is where will find the emergence of patterns desirable to self and other because it involves the awareness that "one knows that how one acts in response to the world changes the world" (ibid, p. 27). Indeed, non-linearity brings attention to the small things we do (or do not do) on a daily basis in each interaction with the world. Seeing and engaging the curriculum of students' lives through complexity thinking bring attention to both what is happening and how one 
is an active participant in that very same happening. To do so would honour teachers and students as co-participants with what Derrida (1995) referred to as a responsibility to leap into uncertainty without knowledge.

\section{Mindfulness as Without-Thinking}

Phenomena can be described in the discourse of complexity as being emergent, having coherence, being in a state of dissonance and chaos, and even all of these states at once. We can concurrently shape our actions by developing conceptual models and acts of engagement that reflect this complexity. The paradox here, however, is that if complexity is thought of as a complete and total description of reality itself, complexity thinking is still one step removed from, but an important finger pointing towards, what is actually happening. I see complexity thinking, even with an emphasis on practicality, as part of what Kabat-Zinn (2005) called 'scaffolding' - instructions, guidelines, contexts, relationships, and languages that give meaning to a journey into experience, nature and the cosmos. Kabat-Zinn made his point about scaffolding through the example of James Clerk Maxwell, the physicist credited with developing the four profound equations that describe the proliferation of electromagnetic fields through space. To do so,

...Maxwell employed a mechanical analogy, a mental model of turning gears to explain to himself how these mysterious, never-before-visualized, incorporeal forces of electricity and magnetism might actually be related to each other. The model was entirely wrong, but it served him as a kind of scaffolding, allowing him to climb to where he was finally able to see, to reach a point where true insight into the nature of the forces he was attempting to understand was possible...the scaffolding was no longer important. (p. 97)

Perhaps complexity thinking is better than a mechanistic model, but I feel that any exclusively conceptual model is still wholly insufficient for closing our experience/action gaps as educators and engaging with the curriculum of students' lives. The insufficiency is not a consequence of failing to build better conceptual models, a critical element in and of itself, but from the nature of this conceptual knowledge. An epistemology of complexity, how we come to know what we know about the universe as complex, must include much more than the enabling constraints of the linguistic-conceptual mind.

Consider Varela's (1999) differentiation between ethical know-how and ethical know-what for seeing ethics as something both unintentionally 'embodied' in our organism and something that is purely abstract, intentional, and rational. He used embodied to refer both to the biological basis of cognition, the body with all of its sensorimotor capacities, and the embodiment of these capacities in biological and cultural contexts. He pointed out that most of our everyday behaviour is not mediated by a deliberating mind that has to think everything through. We are aware of the intention to act 350-400 $\mathrm{ms}$ after the brain has prepared itself to act and about $200 \mathrm{~ms}$ before motor activity (Libet, 1999). Our intention to act is formulated before we even become aware of it.

Varela argued that ethical behaviour has more to do with this immediate coping, this preparing to act, than deliberately willed action (the know-what). We get up in the morning and put our socks on without thought given to how to do it because we have done it so many times - this is our embodied know-how. In more ethically pressing situations, perhaps when someone has fallen, action towards helping this person does not result from judgment and reason, but from what Varela described as an immediate coping with what is confronting us. A relational ethics, then, does not use universal principles and ethical laws originating in and subsequently being applied from a mind independent of the world as its point of departure, but with a bare awareness of how our immediate coping and actions in response to the world change the world. 
Mindfulness is precisely this bare awareness and is the domain of without-thinking, something that includes and goes beyond both thinking as the reification of concepts and non-thinking as the rejection of thinking (Orr, 2002). Mindfulness is cultivated through meditation practices such as zazen and vipassana and is the practice of without-thinking because it "takes no intentional attitude; it neither reifies nor rejects concepts, nor does it involve an identification of the self with them" (ibid, p. 491). Mindfulness is key to a relational ethics because it is a practice and a way of being that aims to cultivate a nonjudgmental and non-conceptual meta-awareness of how the mind (thoughts) and body (sensations) prepare a person to act in response to the world. The meditative traditions show us how our visceral responses are connected to our thoughts and sensory experiences, and that we can liberate ourselves from our attachment to ideas by non-judgmentally observing these very ideas, emotions, and sensations as they manifest in our experience with the world (Orr, 2002).

My aim here is not to describe the theory and practice of mindfulness meditation, but to say that mindfulness is the deep listening required to know, at all levels of experience, the relationship between our conditioned intentions to act and our immediate coping, between our ideas about what we think or do not think is happening and what are experiencing without-thinking. As a form of inner work, mindfulness helps us to see how we make epistemological errors in the classroom and is valuable because it is not itself an ideology. Given these times of under-funded classrooms, mindfulness is also accessible because it is "inherently low-tech and low-cost" (ibid, p. 494).

\section{Concluding Remarks}

In a relational and complex universe, I agree with Bai that we need to take responsibility to the extent that we know how our actions change the world. This responsibility is central to a curriculum of life. Given how humanity has treated the planet and the immense suffering caused by our actions, Education should help us become mindful of our relationships, to the unpredictable and massive impact of our small, seemingly insignificant actions performed day by day, moment by moment. Complexity thinking draws our conceptual attention to how these actions are coupled in self-organizing and non-linear relationships, but it is mindfulness that allows us to experience our immediate coping in these relationships in a non-conceptual, non-judgmental way.

Returning to the concept of a curriculum of life and the importance of listening to the immediate reality of students' lives, I often think about what David Orr (1991) said:

The plain fact is that the planet does not need more "successful" people. But it does desperately need more peacemakers, healers, restorers, storytellers, and lovers of every shape and form. It needs people who live well in their places. It needs people of moral courage willing to join the fight to make the world habitable and humane. And these needs have little to do with success as our culture has defined it. (p. 52)

Our culture has shaped, and has been shaped by, a narrow curriculum of success that does not reflect our need to live well in our places. Learning how to live well (or not live well) in our places, however, is the very education we embody regardless of how our culture defines success. We need more of the people Orr is referring to and we must "worry about the consequences of our responses to the world" (Bai, 2003, p. 27), otherwise we are educating for a world we will not know how to live well in.

\section{Acknowledgment}


The writing of this paper was made possible by a SSHRC Masters Scholarship. 


\section{References}

Bai, H. (2001). Beyond the Educated Mind: Towards a Pedagogy of Mindfulness. In Hocking, B., Haskell, J. \& Linds, W. (Eds.), Unfolding Body/Mind: Exploring Possibility Through Education. Brandon, VT: Foundation for Educational Renewal. pp. 87-99.

Bai, H. (2003). On the Edge of Chaos: Complexity and Ethics. Proceedings of the 2003 Complexity Science and Education Research conference. Edmonton, Canada.

Bereiter, C. (2002). Education And Mind In The Knowledge Age. Hillsdale, NJ: Lawrence Erlbaum Associates.

Burris, E. (2005). Classrooms Can Use Therapy, Too. Complicity: International Journal of Complexity and Education, 2(1). pp. 5-17.

Cohen, A. (2006). Attending to the Inner Life of an Educator: The Human Dimension in Education. Ph.D dissertation University of British Columbia. Retrieved on March 15 th 2007 from http://hdl.handle.net/2429/63

Davis, B. \& Simmt, E. (2003). Understanding learning systems: Mathematics education and complexity science. Journal for Research in Mathematics Education, 34(2). pp. 137-167.

Davis, B. \& Sumara, D. (2006). Complexity and Education: Inquiries into Learning, Pedagogy and Research. Mahwah, NJ: Lawrence Erlbaum Associates.

Dell, P.F. (1982). Beyond Homeostasis: Toward a concept of coherence. Family Process, 21. pp. 21-41.

Derrida, J. (1995). The Gift of Death. Chicago: University of Chicago Press.

Fenwick, T. (2007). Puzzling 'Responsibility': A Complexity Perspective. Paper presented at the 2007 Complexity Science and Education Research Conference. Vancouver, Canada.

Fogel, A. (1993). Developing through relationships: Origins of Communication, Self, and Culture. Chicago: University of Chicago Press.

Fullan, M. (2003). Change Forces with a Vengeance. New York: Routledge Falmer.

Germer, C.K, Siegel, R.D, \& Fulton, P.R. (eds.) (2005). Mindfulness and Psychotherapy. New York: Guilford Press.

Griffin, D. (2002). The Emergence of Leadership: Linking Self-organization and Ethics. New York: Routledge. Heylighen, F., Cilliers, P. \& Gershenson, C. (forthcoming 2007). Complexity and Philosophy. In Bogg, J. \& Geyer, R. (eds.) Complexity, Science and Society. Oxford: Radcliffe Publishing.

Holland, J. (1995). Hidden Order: How Adaptation Builds Complexity. Reading, MA: Addison-Wesley.

Kauffman, S. (1995). At Home in the Universe. New York: Oxford University Press.

Kabat-Zinn, J. (2005). Coming to Our Senses: Healing Ourselves and the World Through Mindfulness. Hyperion: New York.

Libet, B. (1999). Do we have a free will? In B. Libet, A. Freeman, \& K. Sutherland (Eds.), The Volitional Brain: Towards a Neuroscience of Free Will. Thorverton, UK: Imprint Academic.

Maturana, H. \& Varela, F. (1987) The Tree of Knowledge: The Biological Roots of Human Understanding. Boston: Shambhala.

Orr, D. (Winter 1991). What is Education For? Six myths about the foundations of modern education, and six new principles to replace them. The Learning Revolution, 27. Retrieved April 19th, 2007 from http://www.context.org/ICLIB/IC27/TOC27.htm

Orr, D. (2002). The Uses of Mindfulness in Anti-oppressive Pedagogies: Philosophy and Praxis. Canadian Journal of Education, 27(4). pp. 477-490.

Portelli, J. \& Vibert, A. (2001). Beyond common educational standards: Toward a Curriculum of Life. in Portelli, J. \& Solomon, P. (eds.) The Erosion of Democracy in Education. Calgary: Detselig Enterprises Ltd.

Richmon, M. (2006). The Clock and the Waterfall: Leadership, Complexity Science, and the New Phoenix. Paper presented at the annual meeting of the 2006 Canadian Association for the Study of Educational Administration. Toronto, Canada.

Varela, F. J. (1999) Ethical Know-How: Action, Wisdom and Cognition. Stanford, CA: Stanford University Press. 
Varela, F.J., Thompson, E., \& Rosch, E. (1991). The Embodied Mind: Cognitive Science and Human Experience. Cambridge, MA: MIT Press.

\section{About the Author}

Sean Park is an instructor and facilitator in the Bachelor of Health Sciences Programme at McMaster University, Hamilton, ON where he teaches a course on Complex Adaptive Systems. He is a practitioner of vipassana meditation and is currently pursuing graduate studies in complexity and education at the University of Toronto. Send correspondence to sean.park@learnlink.mcmaster.ca 